\title{
Growth characteristics of commercial broiler and native chickens as predicted by different growth functions
}

\author{
A. Moharrery ${ }^{1}$ and M. Mirzaei \\ Shahrekord University, Animal Science Department, Agricultural College, Iran, P.O. Box: 115, Sharekord, Iran
}

Key words: non-linear function, body weight, growth, chicken

Received: 22 July 2013

Revised: 25 November 2013

Accepted: 4 March 2014

${ }^{1}$ Corresponding author:

e-mail: moharrery@agr.sku.ac.ir

\begin{abstract}
This study compared five non-linear growth functions (Gompertz, logistic, Lopez, Richards and Weibull) using body weight (BW) measurements from a commercial strain (Ross 308) and Iranian native chickens. Seventy two commercial broilers and seventy two native chickens were randomly assigned to four treatments. Each treatment consisted of six replicates of three chickens. The chickens were fed with maize-soyabean meal supplying four levels of metabolizable energy (ME) $(100 \%, 94 \%, 88 \%$ and $82 \%$ of NRC recommendations) for eight weeks. Body weight was measured weekly from 2 weeks of age. Flexible growth functions were evaluated for their ability to describe the relationship between liveweight and age, and were compared with functions having a fixed point of inflection. Based on goodness of fit criteria and statistical performance, the flexible growth functions fit the data better than the functions with a fixed point of inflection, such as the Gompertz and logistic functions. Among the flexible growth functions, the Richards function gave the best fit to the data, with adjusted coefficients of determination ranging from 99.51 to 99.12 for commercial and native birds, respectively. The results indicated that commercial broilers had a higher final body weight $\left(W_{f}\right)$ than the native chickens. The chickens receiving $100 \% \mathrm{ME}$ concentrations had higher body weights compared with the chickens on lower energy levels. Based on the Richards function, the decreased dietary ME concentrations caused a linear reduction in $W_{f}$ in the commercial strain $(P<0.05)$; however, dietary energy concentrations had no effect on the $W_{f}$ and other growth curve parameters in native chickens $(P>0.05)$.
\end{abstract}

\section{Introduction}

Analysis of growth is an important component of many biological studies. Growth has been defined as the process of an animal gaining weight with time until it reaches maturity. Application of mathematical models can integrate theories and observations into a coherent framework that can be useful for both conceptual and computational purposes. Historically, researchers have utilized a mathematical function delineated by Gompertz (1825) for describing growth in poultry. Another equation for describing growth in organisms is the logistic function, which is one of the most frequently applied equations for description of sigmoid or S-shaped growth.

The logistic and Gompertz functions have fixed growth forms with points of inflection at about $50 \%$ and $37 \%$ of the asymptote, respectively (Rickleft, 1968). The four-parameter functions such as the Lopez, Weibull and Richards equations with vari- 
able points of inflection, provide a flexible growth function capable of describing sigmoidal and diminishing returns behaviour (Maruyama et al., 1999, 2001; Lopez et al., 2000).

Energy supplying components of animal diets account for approximately $95 \%$ of dry matter (Latshaw and Moritz, 2009). When animals are fed at the maintenance level, all of the dietary metabolizable energy will be converted to heat. Growing birds must eat extra feed to provide additional energy for the synthesis of body tissues. On the other hand, dietary energy has been suggested to be the key input that controls broiler growth trajectory (Aerts et al., 2003). Recently, Nahashon et al. (2010) demonstrated that dietary protein and energy can affect the growth parameters of the French guinea fowl based on the Gompertz-Laired function.

Native broiler chickens have meat quality characteristics that are often favoured by consumers over those of commercial breeds. Therefore, native chicken breeds not only contribute to the conservation of poultry genetic resources, but are also of high economic value.

Therefore, the aims of this study were to 1 . use non-linear functions to describe the growth characteristics of two genetic groups of chickens, a commercial strain (Ross 208 broilers) and Iranian native chickens, and to compare them using criteria related to function selection, 2. to determine the effect of dietary energy concentrations on their growth parameters.

\section{Material and methods}

\section{Birds, diets, management}

A total of 144 one-day-old chickens (72 commercial Ross 308 and 72 Iranian native chickens) were housed separately in floor pens containing litter composed of wood shavings. At one week of age (WOA), each group of chickens was divided into 24 groups, 3 chickens per group, and transferred to metabolism cages $(45 \times 30 \times 25 \mathrm{~cm})$ with mesh flooring in a temperature-controlled room with continuous lighting. The chickens received a maize-based starter diet up to 2 WOA (Table 1). At 2 WOA, birds were weighed individually and each of the 4 experimental diets was fed to 6 groups of chickens for six weeks. The chickens were fed with maize-soyabean meal supplying four levels of metabolizable energy (ME) concentrations $(100 \%, 94 \%, 88 \%$ and $82 \%$ of NRC recommendations 1994) for eight weeks.

The ratio of ME ( $\left.\mathrm{kcal} \cdot \mathrm{kg}^{-1}\right)$ to crude protein (CP) percentage remained constant among all dietary treatments (Table 1). Diets were offered as pellets. Feed and water were provided ad libitum. Room temperature was set at $30^{\circ} \mathrm{C}$ in the second week of life and was then decreased by $0.3^{\circ} \mathrm{C}$ per day to $24^{\circ} \mathrm{C}$, at which time no artificial heating was provided. Body weight was measured weekly from 2 WOA.

Table 1. Composition of the experimental diets

\begin{tabular}{|c|c|c|c|c|c|c|c|c|c|c|c|c|c|}
\hline \multirow{3}{*}{ Indices } & \multirow{3}{*}{ Starter } & \multicolumn{12}{|c|}{ Experimental diets } \\
\hline & & \multicolumn{4}{|c|}{2 to $3 W^{\prime} A^{1}$} & \multicolumn{4}{|c|}{3 to 6 WOA } & \multicolumn{4}{|c|}{6 to 8 WOA } \\
\hline & & 1 & 2 & 3 & 4 & 1 & 2 & 3 & 4 & 1 & 2 & 3 & 4 \\
\hline \multicolumn{14}{|l|}{ Ingredients, \% } \\
\hline ground yellow maize & 61.80 & 49.00 & 55.00 & 50.45 & 56.65 & 53.50 & 55.00 & 50.45 & 56.65 & 57.00 & 60.00 & 61.65 & 61.65 \\
\hline soyabean meal & 28.00 & 35.00 & 38.00 & 32.00 & 26.50 & 34.00 & 38.00 & 32.00 & 26.50 & 28.00 & 23.00 & 19.00 & 15.00 \\
\hline fish meal & 4.95 & 5.50 & & & & & 3.65 & & & & & & \\
\hline plant oil & 1.90 & 7.15 & 3.65 & 3.20 & & 7.15 & & 3.20 & & 7.00 & 4.10 & 2.00 & \\
\hline wheat bran & & & & 11.00 & 13.50 & 2.00 & & 11.00 & 13.50 & 4.65 & 9.55 & 14.00 & 20.00 \\
\hline dicalcium phosphate & 1.20 & 1.20 & 1.20 & 1.20 & 1.20 & 1.20 & 1.20 & 1.20 & 1.20 & 1.20 & 1.20 & 1.20 & 1.20 \\
\hline oyster shell & 1.30 & 1.30 & 1.30 & 1.30 & 1.30 & 1.30 & 1.30 & 1.30 & 1.30 & 1.30 & 1.30 & 1.30 & 1.30 \\
\hline sodium chloride & 0.10 & 0.10 & 0.10 & 0.10 & 0.10 & 0.10 & 0.10 & 0.10 & 0.10 & 0.10 & 0.10 & 0.10 & 0.10 \\
\hline DL- methionine & 0.05 & 0.05 & 0.05 & 0.05 & 0.05 & 0.05 & 0.05 & 0.05 & 0.05 & 0.05 & 0.05 & 0.05 & 0.05 \\
\hline Premix ${ }^{2}$ & 0.70 & 0.70 & 0.70 & 0.70 & 0.70 & 0.70 & 0.70 & 0.70 & 0.70 & 0.70 & 0.70 & 0.70 & 0.70 \\
\hline \multicolumn{14}{|l|}{ Calculated $^{3}$} \\
\hline $\mathrm{AME}, \mathrm{Kcal} \cdot \mathrm{kg}^{-1}$ & 3002 & 3200 & 3010 & 2827 & 2666 & 3200 & 3018 & 2828 & 2643 & 3206 & 3006 & 2851 & 2660 \\
\hline crude protein, \% & 20.78 & 23.00 & 21.50 & 20.28 & 18.79 & 20.02 & 18.91 & 17.80 & 16.54 & 18.10 & 16.93 & 16.01 & 15.19 \\
\hline crude fat, $\%$ & 4.90 & 9.80 & 6.04 & 5.70 & 2.77 & 9.52 & 8.39 & 5.63 & 2.87 & 9.53 & 6.86 & 4.91 & 3.06 \\
\hline methionine, \% & 0.44 & 0.47 & 0.40 & 0.37 & 0.36 & 0.38 & 0.55 & 0.53 & 0.51 & 0.35 & 0.33 & 0.32 & 0.30 \\
\hline lysine, $\%$ & 1.21 & 1.41 & 1.25 & 1.12 & 0.99 & 1.14 & 1.05 & 0.94 & 0.82 & 0.98 & 0.87 & 0.79 & 0.71 \\
\hline $\mathrm{Ca}, \%$ & 1.10 & 1.14 & 0.87 & 0.87 & 0.86 & 0.86 & 1.08 & 1.08 & 1.07 & 0.85 & 0.84 & 0.84 & 0.83 \\
\hline$P$ total, $\%$ & 0.72 & 0.75 & 0.63 & 0.70 & 0.71 & 0.62 & 0.92 & 0.95 & 0.99 & 0.62 & 0.65 & 0.68 & 0.72 \\
\hline
\end{tabular}

${ }^{1}$ WOA - weeks of age, ${ }^{2}$ the premix supplied the following: $\mathrm{mg} \cdot \mathrm{kg}^{-1}$ diet: retinol -3.6 (about $1.1 \mathrm{IU} \cdot \mathrm{KJ}^{-1}$ ), cholecalciferol -0.075 (about $0.26 \mathrm{IU} \cdot \mathrm{KJ}^{-1}$ ), biotin -1 , dl-a-tocopherylacetate -10 , riboflavin - 10, pantothenate -20 , choline -2000 , niacin - 100, thiamine -10 , pyridoxine 10, menadion sodium bisulphate - 1.5, cyanocobalamin - 0.1, folic acid - 2, ethoxyquin - 150, Mn - 100, Fe - 100, Cu - 10, Co - I, I-1, Zn - 100 ${ }^{3}$ estimated from NRC (1994) composition tables 


\section{Growth functions}

To estimate body weight (BW) at a certain age, two 3-parameter and three 4-parameter non-linear functions were fitted to body weight data. The growth functions used in this study were:

Gompertz (Gompertz, 1825):

$$
W=W_{0} \exp \left\{[1-\exp (-k \times \text { Age })] \ln \left(\frac{W_{f}}{W_{0}}\right)\right\}
$$

Logistic (Robertson, 1908):

$$
W=\frac{W_{0} \times W_{f}}{\left[W_{0}+\left(W_{f}-W_{0}\right) \exp (-k \times \text { Age })\right]}
$$

Lopez (Lopez et al., 2000):

$$
W=\frac{\left(W_{0} \times K_{n}\right)+\left(W_{f} \times \mathrm{Age}_{n}\right)}{\left(K_{n}+\mathrm{Age}_{n}\right)}
$$

Richards (Richards, 1959):

$$
W=\frac{W_{0} \times W_{f}}{\left[W_{0}+\left(W_{f}-W_{0}\right) \exp (-k \times \text { Age })\right]^{1 / m}}
$$

Weibull (Maruyama et al., 1999, 2001):

$$
W=W_{f}-\left(W_{f}-B\right) \exp \left[-\left(\frac{C-1}{C}\right)\left(\frac{\text { Age }}{t}\right)^{C}\right]
$$

where: $W-$ the expected $\mathrm{BW}$ at a given age, $W_{f}-$ the asymptotic $\mathrm{BW}$ of the chickens, $W_{0}$ - the initial $\mathrm{BW}, t-$ the age at the inflexion point; $K$ - the age to approximately one-half maximum BW, $m$ - a shape parameter, and $B, C, k, n$ - constants.

The general differential form of a growth function is $\mathrm{d} W / \mathrm{dAge}=f(W$, Age $)$, which means that the growth rate of a biological system is dependent on the liveweight and age. A growth function, however, can characterize some underlying physiological or biological mechanisms or constraints (Darmani Kuhi et al., 2003). Some properties of growth functions are shown in Table 2.

\section{Statistical procedures}

The growth functions were fitted to the measurements of liveweights related to age via a nonlinear procedure using the Marquardt algorithm of SAS (2009).

Several statistics are used to determine the goodness of fit. The coefficient of determination $\left(r^{2}\right)$ and adjusted coefficient of determination $\left(R^{2}\right)$ are the most common ones used to compare the performances of the estimated functions. The accuracy of function selection can be increased by including other selection criteria. In this respect, the functions fitted to the data were compared by using the goodness of fit statistics listed below:

Coefficient of determination: $=1-(\mathrm{RSS} / \mathrm{SST})$,

where: RSS - the residual sum of square, SST - the total sum of squares.

Adjusted coefficient of determination:

$$
R^{2}=r^{2}-\left[\frac{(k-1)\left(1-r^{2}\right)}{n-k}\right]
$$

where: $n$ - the number of observations, $k$ - the number of parameters included in the function.

RSS was used to compare the functions. The fit with the smallest RSS and the same number of parameters was selected as the superior fit. The statistical significance between functions in terms of the goodness-of-fit was assessed using an $\mathrm{F}$ test (Darmani Kuhi et al., 2003). For functions with the same number of parameters, an $F$ test in the form of $\mathrm{F}=\mathrm{RSS}_{1} / \mathrm{RSS}_{2}$ was used in which the subscripts

\begin{tabular}{|c|c|c|c|c|}
\hline Model & Age at inflection point & Weight at inflection point & Growth rate $(d W / d A g e)$ & Reference \\
\hline Gompertz & $\frac{1}{k}\left[\ln \left(\ln \left(\frac{W_{f}}{W_{0}}\right)\right)\right]$ & $\frac{W_{f}}{e}$ & $k W \ln \left(\frac{W_{f}}{W}\right)$ & Gompertz,1825 \\
\hline Logistic & $\frac{1}{k} \ln \left(\frac{W_{f}-W_{0}}{W_{0}}\right) \ln$ & $\frac{W_{f}}{2}$ & $n W\left(1-\frac{W_{f}}{W}\right)$ & Robertson, 1908 \\
\hline Lopez & $k\left(\frac{n-1}{n+1}\right)^{1 / 2}$ & $\frac{\left.\left(1+\frac{1}{n}\right) W_{0}+\left(1-\frac{1}{n}\right) w_{f}\right)}{2}$ & $n\left(\frac{\mathrm{Age}^{n-1}}{K^{n}+\mathrm{Age}^{n}}\right)\left(W_{t}-W\right)$ & Lopez et al., 2000 \\
\hline Richards & $\frac{1}{\mathrm{k}} \times \ln \left(\frac{m}{\left(W_{f}^{m}-W_{0}^{m}\right) / W_{0}^{m}}\right)$ & $\frac{W}{\sqrt[m]{m+1}}$ & $k \times W\left(\frac{W_{f}^{m}-W^{m}}{m W_{f}^{m}}\right)$ & Richards, 1959 \\
\hline Weibull & $\frac{1}{\left(1-\frac{1}{a \ln 2}\right)}$ & $W_{f}-\left(W_{f}-B\right) \exp \left[-\left(\frac{C-1}{C}\right)\right]$ & $\frac{W_{f} \alpha \ln 2}{2 \times A g e}$ & Maruyama et al., 1999, 2001 \\
\hline
\end{tabular}
1 and 2 refer to the fit with larger and smaller RSS values, respectively. The functions with different numbers of parameters were tested using the following $\mathrm{F}$ test (Motulsky and Ransnas, 1987):

Table 2. Growth rate, age at inflection point and weight at inflection point of the different growth models

$W$ - predicted body weight at a given age; $W_{f}$ - the asymptotic weight; $W_{0}$ - the initial weight; $K$ - the age to approximately one-half maximum weight, $m$ - a shape parameter, $B, C, e, k, n, \alpha, \lambda$, are constants 


$$
F=\frac{\left(\mathrm{RSS}_{1}-\mathrm{RSS}_{2}\right) /\left(d f_{1}-d f_{2}\right)}{\mathrm{RSS}_{2} / d f_{2}}
$$

in which $d f$ - the degree of freedom. The subscript 1 refers to the fit with fewer parameters, i.e. the simpler function. $\mathrm{H} 0$ means that all functions have the same RSS.

The differences in growth parameters for two strains were tested using the general linear model procedure of SAS (2009). A complete randomized design arranged as a $2 \times 4$ factorial experiment was used to indicate significant differences in growth as affected by the dietary ME concentration $(P<0.05)$. The data were analysed using the general linear model procedure of SAS (2009). Duncan's multiple range test $(P<0.05)$ was used to test the significance of differences between means.

\section{Results}

The estimated parameters for the applied functions in the commercial strain and native chickens are presented in Table 3. Parameter values are shown together with their standard errors (SE) when the software was able to calculate it. Growth functions could be fitted by non-linear regression in both genetic groups. For all five functions, the parameter $W_{f}$, which is defined as asymptotic final BW, was greater for the commercial strain than for the native birds. Parameter $k$, which is interpreted as the rate of exponential decay of the initial growth rate, was identical in both genetic groups. Both genetic groups reached an inflection point at the same age. All nonlinear functions showed that the commercial strain had a 2.5 -fold greater weight at the inflection point and final BW $\left(W_{f}\right)$ than the native chickens.

The RSS values, as criteria for the goodness of fit, showed that the logistic and Gompertz equations were not able to produce a suitable fit, but the other growth functions provided a perfect fit, especially for the native chicken. Among the four-parameter functions (Lopez, Richards and Weibull), the Richards function showed the smallest RSS value. The RSS value was larger for the Gompertz function compared with the logistic one. The Richards function was superior to other functions, because the fit in both genetic groups led to lower RSS values and, therefore, to a better fit to the data. Nonetheless, based on adjusted determination coefficients $\left(R^{2}\right)$, with a minimum and maximum value of $99.14 \%$ and $99.51 \%$ for the commercial strain and a minimum and maximum value of $98.71 \%$ and $99.12 \%$ for native chickens, none of the functions was superior to other functions.

If the functions fit the data with sensible values, and the more complicated function (the one with more parameters) fits better, statistical calculations are used to decide which function is to be accepted. Goodness-of-fit was assessed using an F test. The statistical $\mathrm{F}$ tests among the functions, based on the RSS value, for the functions with the same and with different numbers of parameters are shown in Table 4. The $F$ test comparison between the logistic and Gompertz functions (which have the same number of parameters) showed no significant difference between these functions in either genetic group. The four-parameter functions (with the exception of the Lopez function) were superior to the Gompertz and logistic functions for both genetic groups. The Lopez function was superior to the logistic function only in the commercial strain. In both genetic groups, the Richards function provided a better fit compared with the other flexible growth functions. In the commercial strain, the Weibull function provided only a $4.17 \%$ better fit compared with the Richards function.

Table 3. The estimated growth parameters in two genetic groups of broilers using different growth models

\begin{tabular}{lllllllll}
\hline \multicolumn{2}{c}{$W_{0}$} & $W_{f}$ & $k$ & $t_{i}$ & $W_{i}$ & $W_{i} / W_{f}$ & RSS & Adjusted $r^{2}$ \\
\hline \multicolumn{2}{l}{ Commercial strain (Ross 308) } & & & & & & & \\
$\quad$ Gompertz & $26.5(15.46)$ & $5729(1718.1)$ & $0.0334(0.0064)$ & $52.5(10.38)$ & $2108(632.3)$ & 0.368 & 19800 & 99.14 \\
Logistic & $71.3(17.65)$ & $3338(619.2)$ & $0.0836(0.0118)$ & $46.6(5.98)$ & $1669(309.6)$ & 0.5 & 12254 & 99.45 \\
Lopez & $228(47.9)$ & $4044(1586.9)$ & $3.795(0.679)$ & $80.4(23.2)$ & $1580(432.4)$ & $0.404(0.042)$ & 8712 & 99.47 \\
Richards & $87.9(26.23)$ & $2683(567.2)$ & $0.201(0.138)$ & $45.0(2.99)$ & $1574(211.2)$ & $0.603(0.104)$ & 7841 & 99.51 \\
$\quad$ Weibull & $215(52.7)$ & $2958(720.0)$ & $3.436(0.538)$ & - & $1582(304.8)$ & $0.541(0.039)$ & 8379 & 99.49 \\
Native chicken & & & & & & & & \\
Gompertz & $27.8(11.13)$ & $2347(1496.6)$ & $0.0301(0.0074)$ & $52.9(18.74)$ & $864(550.7)$ & 0.368 & 3577 & 98.79 \\
Logistic & $47.6(10.95)$ & $1241(309.7)$ & $0.0741(0.0049)$ & $44.1(6.68)$ & $620(154.9)$ & 0.5 & 2923 & 99.00 \\
Lopez & $105(24.6)$ & $1692(973.9)$ & $3.126(0.730)$ & $86.5(29.8)$ & $609.5(249.2)$ & $0.382(0.056)$ & 2777 & 98.71 \\
Richards & $55.6(17.2)$ & $1055(360.9)$ & $0.714(1.642)$ & $43.9(4.39)$ & $628(125.3)$ & $0.632(0.169)$ & 1847 & 99.12 \\
Weibull & $102(27.6)$ & $1145(385.2)$ & $2.907(0.598)$ & - & $588(148.7)$ & $0.524(0.050)$ & 2596 & 98.79 \\
\hline
\end{tabular}

value in the parentheses is standard error

$W_{-}$- the initial weight, $g ; W_{f}$ - the final weight, $g ; k$ - the rate of exponential decay of the initial growth rate; $t_{-}-$time of maximum growth, day; $W_{-}$- weight at inflection point, $g$; RSS - residual sum of squares 
Table 4. The statistical significances $(P<0.05)$ between models based on residual sum of squares

\begin{tabular}{|c|c|c|c|c|c|}
\hline \multirow{2}{*}{ Model } & \multicolumn{3}{|c|}{ Gompertz Logistic Lopez } & \multirow[t]{2}{*}{ Richards } & \multirow[t]{2}{*}{ Weibull } \\
\hline & \multicolumn{3}{|c|}{ Commercial strain (Ross 308) } & & \\
\hline Gompertz & - & $0.0^{1}$ & 0.0 & 33.33 & 29.17 \\
\hline Logistic & & - & 4.17 & 16.67 & 4.17 \\
\hline Lopez & & & - & 0.0 & 0.0 \\
\hline Richards & & & & - & 4.17 \\
\hline Weibull & & & & & - \\
\hline \multicolumn{6}{|c|}{ Native chicken } \\
\hline Gompertz & - & 0.0 & 0.0 & 12.5 & 4.17 \\
\hline Logistic & & - & 0.0 & 8.33 & 0.0 \\
\hline Lopez & & & - & 4.17 & 0.0 \\
\hline Richards & & & & - & 0.0 \\
\hline Weibull & & & & & - \\
\hline
\end{tabular}

${ }^{1}$ percentage of cases in which the model specified in the column was significant $(P<0.05)$ superior to the model specified in the row
The means and SEM of predicted growth parameters are presented in Tables 5 and 6 . The five growth functions showed different behaviours, which were initialized by $W_{0}$ and ended at $W_{f}$ The effect of dietary ME concentration on growth parameters was significant $(P<0.05)$ in both genetic groups, but with different patterns in each growth function. The time of maximum growth $\left(t_{i}\right)$, predicted by the Gompertz function, was significantly higher $(P<0.05)$ in commercial-strain birds fed diets containing $3008 \mathrm{kcal}$ of $\mathrm{ME} \cdot \mathrm{kg}^{-1}$, but not in the native birds.

Based on function behaviour, the Richards function provided an excellent fit to both genetic groups. Based on the Richards function, $W_{f}$ was affected by ME concentration in the commercial strain (Table 5), with the chickens on the diet containing 3200 $\mathrm{kcal}$ of $\mathrm{ME} \cdot \mathrm{kg}^{-1}$ showing the highest $W_{f}$ and those

Table 5. Model coefficient in commercial Ross 308 strain fed diets with varying metabolizable energy concentration

\begin{tabular}{|c|c|c|c|c|c|c|c|}
\hline \multirow[t]{2}{*}{ ME concentration, $\mathrm{kcal} \cdot \mathrm{kg}^{-1}$} & \multicolumn{7}{|c|}{ Growth model coefficients } \\
\hline & $W_{0}$ & $W_{f}$ & $k$ & $t_{i}$ & $W_{i}$ & RSS & adjusted $r^{2}$ \\
\hline \multicolumn{8}{|l|}{ Gompertz } \\
\hline 3200 & $26.2^{b}$ & 5809 & 0.1849 & $50.1^{\mathrm{ab}}$ & 2138 & 26168 & 99.01 \\
\hline 3008 & $47.3^{\mathrm{a}}$ & 6955 & 0.1399 & $63.6^{a}$ & 2559 & 7938 & 99.62 \\
\hline 2828 & $19.1^{\mathrm{b}}$ & 4752 & 0.2016 & $46.9^{b}$ & 1748 & 20446 & 99.07 \\
\hline 2658 & $22.7^{\mathrm{b}}$ & 5636 & 0.1960 & $51.8^{\mathrm{ab}}$ & 2074 & 22648 & 98.92 \\
\hline SEM & 6.82 & 881.1 & 0.0211 & 4.74 & 324.2 & & \\
\hline \multicolumn{8}{|l|}{ Logistic } \\
\hline 3200 & 68.7 & 3318 & 0.0892 & $43.3^{b}$ & 1659 & 18177 & 99.32 \\
\hline 3008 & 86.2 & 3737 & 0.0744 & $51.0^{a}$ & 1869 & 4759 & 99.76 \\
\hline 2828 & 65.4 & 3253 & 0.0853 & $46.3^{a b}$ & 1627 & 12496 & 99.41 \\
\hline 2658 & 65.0 & 3043 & 0.0857 & $46.0^{\mathrm{ab}}$ & 1522 & 13585 & 99.31 \\
\hline SEM & 6.67 & 246.6 & 0.0049 & 2.31 & 123.3 & & \\
\hline \multicolumn{8}{|l|}{ Lopez } \\
\hline 3200 & 234 & $3825^{b}$ & $3.869^{a}$ & $72.6^{b}$ & $1529^{b}$ & 13667 & 99.31 \\
\hline 3008 & 208 & $5744^{a}$ & $3.121^{b}$ & $105.6^{a}$ & $2026^{a}$ & 4484 & 99.70 \\
\hline 2828 & 230 & $3579^{b}$ & $3.986^{\mathrm{a}}$ & $74.4^{b}$ & $1464^{b}$ & 9055 & 99.43 \\
\hline 2658 & 241 & $3028^{b}$ & $4.204^{a}$ & $68.9^{b}$ & $1301^{b}$ & 7642 & 99.46 \\
\hline SEM & 20.3 & 522.9 & 0.234 & 7.74 & 145.6 & & \\
\hline \multicolumn{8}{|l|}{ Richards } \\
\hline 3200 & 81.8 & $3120^{a}$ & 0.1787 & 43.8 & 1708 & 10573 & 99.43 \\
\hline 3008 & 101.8 & $2705^{a b}$ & 0.1633 & 47.1 & 1609 & 3076 & 99.78 \\
\hline 2828 & 84.8 & $2491^{a b}$ & 0.2088 & 44.5 & 1519 & 7912 & 99.49 \\
\hline 2658 & 83.4 & $2416^{b}$ & 0.2537 & 44.4 & 1463 & 9803 & 99.35 \\
\hline SEM & 10.9 & 216.0 & 0.0583 & 1.17 & 82.5 & & \\
\hline \multicolumn{8}{|l|}{ Weibull } \\
\hline 3200 & 217 & $3031^{\mathrm{ab}}$ & 3.459 ab & $42.6^{b}$ & $1614^{\mathrm{ab}}$ & 12425 & 99.36 \\
\hline 3008 & 204 & $3648^{a}$ & $2.999^{b}$ & $51.2^{\mathrm{a}}$ & $1856^{a}$ & 4261 & 99.71 \\
\hline 2828 & 217 & $2706^{b}$ & 3.589 & $44.0^{\mathrm{b}}$ & $1487^{b}$ & 8468 & 99.46 \\
\hline 2658 & 224 & $2445^{b}$ & $3.698^{a}$ & $42.9^{b}$ & $1371^{b}$ & 8364 & 99.43 \\
\hline SEM & 22.9 & 242.8 & 0.204 & 1.82 & 106.5 & & \\
\hline
\end{tabular}

$\mathrm{ME}$ - metabolizable energy in the diets; $W_{0}$ - the initial weight, $g ; W_{f}$ - the final weight, $g ; k$ - the rate of exponential decay of the initial growth rate; $t_{i}$ - time of maximum growth, day; $W_{i}$ - weight at inflection point, $g$; RSS - residual sum of square within columns and for each function, means with no common superscript differ significantly $(P<0.05)$ SEM - standard error of the mean 
Table 6. Model coefficient in native chickens fed diets with varying metabolizable energy concentration

\begin{tabular}{|c|c|c|c|c|c|c|c|}
\hline \multirow[t]{2}{*}{$\mathrm{ME}, \mathrm{kcal} \cdot \mathrm{kg}^{-1}$} & \multicolumn{7}{|c|}{ Growth model coefficients } \\
\hline & $W_{0}$ & $W_{f}$ & $k$ & $t_{i}$ & $W_{i}$ & RSS & adjusted $r^{2}$ \\
\hline \multicolumn{8}{|l|}{ Gompertz } \\
\hline 3200 & $22.5^{b}$ & 1735 & $0.1545^{\mathrm{a}}$ & 42.6 & 638 & 4574 & 98.76 \\
\hline 3008 & $36.7^{\mathrm{a}}$ & 2814 & $0.1135^{b}$ & 59.6 & 1036 & 4212 & 98.44 \\
\hline 2828 & $30.1^{\mathrm{ab}}$ & 2445 & $0.1136^{b}$ & 57.2 & 900 & 2769 & 98.94 \\
\hline 2658 & $23.4^{\mathrm{ab}}$ & 2472 & $0.1386^{a b}$ & 53.4 & 610 & 2752 & 99.00 \\
\hline SEM & 4.30 & 648.8 & 0.1230 & 7.88 & 238.8 & & \\
\hline \multicolumn{8}{|l|}{ Logistic } \\
\hline 3200 & $43.5^{b}$ & 1135 & $0.0816^{a}$ & 39.7 & 568 & 2985 & 99.19 \\
\hline 3008 & $57.8^{a}$ & 1353 & $0.0666^{b}$ & 47.6 & 676 & 3889 & 98.56 \\
\hline 2828 & $46.9^{a b}$ & 1265 & $0.0716^{b}$ & 45.5 & 633 & 2277 & 99.14 \\
\hline 2658 & $42.3^{b}$ & 1211 & $0.0767^{\mathrm{ab}}$ & 43.5 & 605 & 2543 & 99.10 \\
\hline SEM & 3.94 & 130.9 & 0.0037 & 2.62 & 65.4 & & \\
\hline \multicolumn{8}{|l|}{ Lopez } \\
\hline 3200 & 123.7 & 1239 & $3.612^{\mathrm{a}}$ & 67.5 & 521 & 2646 & 99.00 \\
\hline 3008 & 99.9 & 2083 & $2.611^{b}$ & 104.0 & 696 & 4115 & 97.97 \\
\hline 2828 & 100.1 & 2054 & $3.027^{\mathrm{ab}}$ & 99.3 & 693 & 2187 & 98.90 \\
\hline 2658 & 92.6 & 1409 & $3.175^{\mathrm{ab}}$ & 76.4 & 529 & 2162 & 98.97 \\
\hline SEM & 9.86 & 412.4 & 0.2918 & 11.7 & 107.9 & & \\
\hline \multicolumn{8}{|l|}{ Richards } \\
\hline 3200 & $62.9^{a}$ & 936 & 0.2432 & 41.7 & 618 & 1277 & 99.49 \\
\hline 3008 & $66.3^{a}$ & 884 & 0.7819 & 43.8 & 602 & 2907 & 98.50 \\
\hline 2828 & $54.7^{\mathrm{ab}}$ & 1180 & 0.8097 & 46.9 & 677 & 1655 & 99.19 \\
\hline 2658 & $37.0^{b}$ & 1218 & 1.0979 & 43.0 & 608 & 1550 & 99.32 \\
\hline SEM & 6.02 & 152.1 & 0.6592 & 1.80 & 56.1 & & \\
\hline \multicolumn{8}{|l|}{ Weibull } \\
\hline 3200 & $120.2^{\mathrm{a}}$ & 989 & 3.260 & $38.9^{b}$ & 551 & 2128 & 99.19 \\
\hline 3008 & $103.7^{\mathrm{ab}}$ & 1125 & 2.610 & $42.8^{a b}$ & 573 & 4039 & 98.00 \\
\hline 2828 & $98.6^{\mathrm{ab}}$ & 1351 & 2.845 & $46.5^{a}$ & 666 & 2108 & 98.94 \\
\hline 2658 & $84.1^{b}$ & 1105 & 2.857 & $40.9^{a b}$ & 555 & 2110 & 99.01 \\
\hline SEM & 11.17 & 165.8 & 0.2521 & 2.10 & 64.74 & & \\
\hline
\end{tabular}

ME - metabolizable energy in the diets; $W_{0}$ - the initial weight, $g ; W_{f}$ - the final weight, $g ; k$ - the rate of exponential decay of the initial growth rate; $t_{i}$ - time of maximum growth, day; $W_{i}$ - weight at inflection point, g; RSS - residual sum of square within columns and for each function, means with no common superscript differ significantly $(P<0.05)$ SEM - standard error of the mean

on the diet containing the lowest ME concentration $\left(2658 \mathrm{kcal}\right.$ of $\left.\mathrm{ME} \cdot \mathrm{kg}^{-1}\right)$ showing the smallest $W_{f}$ $(P<0.05)$. The final body weight $\left(W_{f}\right)$ was not affected $(P>0.05)$ by dietary ME concentration in the native birds. The differences in the $k$ parameter, time of maximum growth $\left(t_{i}\right)$, and body weight at time at inflection point $\left(W_{i}\right)$ among dietary ME levels were not significant in either genetic group $(P>0.05)$.

Growth data from both genetic groups at different ages were pooled and compared for the effect of ME concentration (Table 7). As expected, commercial birds grew faster at all WOA compared with the native birds. The body weight at different WOA was affected by the dietary ME concentration, and chickens on $100 \%$ NRC recommendation (1994) for ME concentrations. No significant difference $(P>0.05)$ was observed for body weight at different WOA for
Table 7. Mean of body weight (g) at different weeks of age (WOA)

\begin{tabular}{|c|c|c|c|c|c|c|c|}
\hline \multirow{2}{*}{\multicolumn{3}{|c|}{$\begin{array}{l}\text { WOA Genetic group } \\
\qquad \begin{array}{c}\text { Commercial Native } \\
\end{array}\end{array}$}} & \multicolumn{5}{|c|}{ ME in the diet, $\mathrm{kcal} \cdot \mathrm{kg}^{-1}$} \\
\hline & & & \multirow{2}{*}{\multicolumn{2}{|c|}{$\begin{array}{c}32003008 \quad 2828 \\
191^{\mathrm{a}} 179^{\mathrm{ab}} 173^{\mathrm{b}}\end{array}$}} & \multirow{2}{*}{$\frac{2658}{184^{\mathrm{ab}}}$} & \multicolumn{2}{|c|}{ Interaction*RMSE } \\
\hline & $242^{a}$ & $122^{\mathrm{b}}$ & & & & 0.5013 & 16.11 \\
\hline & $386^{a}$ & $205^{b}$ & $323^{a} 307^{a}$ & $289^{b}$ & $265^{c}$ & 0. & 24.08 \\
\hline & 575 & 285 & $467^{\mathrm{a}} 430^{\mathrm{at}}$ & $415^{b}$ & 40 & & 50. \\
\hline & 97 & $429^{b}$ & $795^{a} 652^{b}$ & $669^{b}$ & $681^{b}$ & 0. & 97.19 \\
\hline & $1397^{a}$ & $564^{b}$ & $1092^{\mathrm{a}} 901^{\mathrm{b}}$ & $966^{b}$ & 962 & 0 & 142.27 \\
\hline & 1835 & $725^{b}$ & $1433^{a} 1203^{b}$ & $1259^{b}$ & $1226^{b}$ & 0.27 & 188.66 \\
\hline & $2246^{a}$ & $846^{b}$ & $1689^{\mathrm{a}} 1476^{\mathrm{b}}$ & $1528^{\mathrm{ab}}$ & b $1490^{b}$ & 0.2440 & 217.48 \\
\hline
\end{tabular}

* probability for interaction of genetic group $\times$ diet ME concentration RMSE - root mean square of error

within rows, means with no common superscript differ significantly $(P<0.05)$

other levels of diet ME concentration (Table 7). The interaction between genetic background and dietary ME concentration on body weight at various WOA was not significant $(P>0.05)$. 


\section{Discussion}

Growth curves are often non-linear sigmoidal functions parameterized to include an asymptote and an inflection point. The non-linear functions have been used extensively to model animal growth (Thornley and France, 2007). Assuming an appropriate growth function, the accuracy of function parameters depends on the accuracy of the data. The data set of the current study was collected from two genetic groups of chickens (a commercial strain and Iranian native chickens) assigned to four levels of ME concentration in their diets with weekly BW recording over different phases of the growth period. As expected, and according to all growth functions in this study, Iranian native birds grew slower with a final weight that was 2.5 times smaller than that of the commercial Ross 308 strain. This is in agreement with Lin et al. (2010) who reported that compared with Taiwanese native chickens, commercial broilers grew faster, consumed more feed and converted feed into gain more efficiently. Selection for heavier BW in commercial broiler chickens and change in their growth through genetic selection is well documented (Havenstein et al., 2003).

Dietary ME is a key input that controls broiler growth trajectory (Aerts et al., 2003). In addition, mathematical functions of growth in poultry have played a key role in poultry improvement programmes (Nahashon et al., 2010). The evolution of such mathematical functions as Gompertz, logistic, Lopez, Richards and Weibull to describe population growth clearly indicates how this field has developed over the years. However, both the logistic and Gompertz have points of inflection that are always at a fixed proportion of their asymptotic population values (France and Thornley, 1984). Therefore, in the present study, two functions with a fixed point of inflection, the Gompertz and the logistic, were evaluated with regard to their ability to describe the relationship between liveweight and age in two chicken strains and compared with three flexible growth functions, namely the Lopez, the Richards and the Weibull. When comparing the fits of two functions, the first step is to examine the best-fit values of each function to make sure they are scientifically reasonable. Comparison of adjusted determination coefficients $\left(R^{2}\right)$, showed that none of the functions was significantly superior to others. This result was in agreement with Darmani Kuhi et al. (2003) who found no significant difference among functions with a fixed point of inflection and flexible growth functions in male and female broilers.
Based on RSS values, the Richards and Gompertz functions gave the best and the worst fits, respectively. In agreement with this finding, the superiority of the Richards function, for its ability to function the growth curve of broiler chickens (male and female) and Ross 308 broiler parent flocks has been reported by other researchers (Darmani Kuhi et al., 2003; Tompić et al., 2011).

The $\mathrm{F}$ test compares the fit of two equations, where the more complicated equation (the one with more parameters) fits better (has a smaller RSS) than the simple equation. There is no need, however, for statistical calculations to reject a function if the best-fit parameters of that function are not scientifically relevant. Therefore, if the more complicated function does not provide a fit (has higher RSS) that is superior to the simpler function, then it should clearly be rejected. This will happen rarely, as the curve generated by the more complicated function (the one with more parameters) will nearly always have a lower RSS, simply because it has more inflection points.

Based on the F test criterion, the Richards and the Weibull functions were superior to other functions (Table 4). Although flexible growth functions always have statistically significant parameter estimates, this should not be the sole criterion in selecting a growth function. For example, with the Weibull and Lopez functions, the biologically meaningful parameters did not suggest a suitable fit in our chickens, but fitting the function led to statistically significant parameter estimates.

With all criteria included, the Richards function was superior to other functions in both genetic groups. The final body weight $(W)$ of commercial birds fed the $3200 \mathrm{kcal} \mathrm{ME} \cdot \mathrm{kg}^{-1}$ diet was significantly greater than those of birds fed the lower ME concentration in their diets (Table 5). Such a trend was not found in the native birds, however (Table 6). Metabolizable energy intake affects BW and composition (Boekholt et al., 1994; Wiseman and Lewis, 1998). Geneticists have selected broilers for many years to grow faster and achieve a bigger size sooner (Havenstein et al., 2003). The function suggests that one explanation for this is selection for greater daily energy intake due to the high concentration of ME in their diets. It has also been shown that final body weight $\left(W_{f}\right)$ was significantly greater in guinea fowl broilers fed either the 3,100 or 3,150 $\mathrm{kcal} \mathrm{ME} \cdot \mathrm{kg}^{-1}$ diet than those fed the 3,050 kcal $\mathrm{ME} \cdot \mathrm{kg}^{-1}$ diet (Nahashon et al., 2005). The differences between the two genetic groups in relation to the effects of ME concentration on $W_{f}$ can be due to adaptation of the native birds in consuming feed of 
a lower ME concentration. In addition, native birds have a slower growth rate and reach a smaller size at maturity than commercial birds. This means that they do not need high energy concentrations in their feed. Therefore, when native birds are fed diets containing a high level of ME, they will reduce their feed intake to control their energy consumption. This may be a reason for the lack of effect of dietary ME level on $W_{f}$ in these native chickens. Leeson et al. (1996) reported that the birds regulated their intake to maintain a similar ME intake. In contrast to native birds, Plumstead et al. (2007) found no difference in feed intake of commercial broilers fed dietary energy levels ranging from 3000 to $3200 \mathrm{kcal} /$ $\mathrm{kg}$. This means that the broilers on high-level energy concentrations received more energy, which resulted in a heavier body weight. The authors suggested that the lack of regulation of feed intake may be due to the intense genetic selection for growth over the years in modern broiler chickens affecting satiety mechanisms. Therefore, this kind of information is important in nutritional management because it allows the producer to match the requirements by adjusting what is fed to the animal when the growth rate is at its maximum.

\section{Conclusions}

Comparison of five growth functions in terms of goodness of fit criteria revealed that the four-parameter functions (especially the Richards function) were the most appropriate functions for describing the age-related changes in body weight of Ross commercial broilers and Iranian native chickens. Special attention should be paid to characterization of the growth pattern of birds under different environmental conditions or from different lines. Further studies are needed to determine the most appropriate function for use in broiler breeding and management.

\section{Acknowledgements}

The financial support of the Research Department of Shahrekord University is gratefully acknowledged. The authors are also thankful to Prof. M.J. Zamiri (Senior Scientist of Shiraz University, Shiraz, Iran) for his comments on this paper.

\section{References}

Aerts J.M., Lippens M., De Groote G., Buyse J., Decuypere E., Vranken E., Berckmans D., 2003. Recursive prediction of broiler growth response to feed intake by using a time-variant parameter estimation method. Poultry Sci. 82, 40-49

Boekholt H.A., Van Der Grintin P.H., Schreurs V.V.A.M., Los M.J.N., Leffering C.P., 1994. Effect of dietary energy restrictions on retention of protein, fat and energy in broiler chickens. Brit. Poultry Sci. 35, 603-614

Darmani Kuhi H., Kebreab E., Lopez S., France J., 2003. An evaluation of different growth functions for describing the profile of live weight with time (age) in meat and egg strains of chicken. Poultry Sci. 82, 1536-1543

France J., Thornley J.H.M., 1984. Mathematical Models in Agriculture. Butterworths, London

Gompertz B., 1825. On the nature of the function expressive of the law of human mortality and on a new method of determining the value of life contingencies. Trans. R. Philos. Soc. 115, 513-585

Havenstein G.B., Ferket P.R., Qureshi M.A., 2003. Growth, livability, and feed conversion of 1957 versus 2001 broilers when fed representative 1957 and 2001 diets. Poultry Sci. 82, 1500-1508

Latshaw J.D., Moritz J.S., 2009. The partitioning of metabolizable energy by broiler chickens. Poultry Sci. 88, 98-105

Leeson S., Caston L., Summers J.D., 1996. Broiler response to diet energy. Poultry Sci. 75, 529-535

Lin C.S., Chiang S.H., Lu M.Y., 2010. Comparison of the energy utilisation of conventional and Taiwanese native male broilers. Anim. Feed Sci. Tech. 161, 149-154

Lopez S., France J., Dhanoa M.S., Mould F., Dijkstra J., 2000. A generalized Michaelis-Menten equation for the analysis of growth. J. Anim. Sci. 78, 1816-1828

Maruyama K., Akbar M.K., Turk C.M., 1999. Growth pattern and carcase development in male ducks selected for growth rate. Brit. Poultry Sci. 40, 233-239

Maruyama K., Vinyard B., Akbar M.K., Shafer D.J, Turk C.M., 2001. Growth curve analyses in selected duck lines. Brit. Poultry Sci. 42, 574-582

Motulsky H.J., Ransnas L.A., 1987. Fitting curves to data using nonlinear regression:A practical and nonmathematical review. FASEB J. 1, 365-374

Nahashon S.N., Adefope N., Amenyenu A., Wright D., 2005. Effect of dietary metabolizable energy and crude protein concentrations on growth performance and carcass characteristics of French guinea broilers. Poultry Sci. 84, 337-344

Nahashon S.N., Aggrey S.E., Adefope N.A., Amenyenu A., Wright D., 2010. Gompertz-Laird model prediction of optimum utilization of crude protein and metabolizable energy by French guinea fowl broilers. Poultry Sci. 89, 52-57

NRC, 1994. Nutrient Requirements of Poultry. $9^{\text {th }}$ Edition. National Academy Press. Washington, DC

Plumstead P.W., Romero-Sanchez H., Paton N.D., Spears J.W., Brake J., 2007. Effects of dietary metabolizable energy and protein on early growth responses of broilers to dietary lysine. Poultry Sci. 86, 2639-2648

Richards F.J., 1959. A flexible growth function for empirical use. J. Exp. Bot. 10, 290-300

Rickleft R.E., 1968. Patterns of growth in birds. Ibis 110, 419-451

Robertson T. B., 1908. On the normal rate of growth of an individual and its biochemical significance. Arch. Entwicklungsmech. Org. 25, 581-614

SAS, 2009. Version 9.3. SAS Institute Inc. Cary, NC

Thornley J.H.M., France J., 2007. Mathematical Models in Agriculture. $2^{\text {nd }}$ Edition. CABI Publication, Wallingford, UK. pp. 136-169

Tompić T., Dobša J., Legen S., Tompić N., Medić H., 2011. Modeling the growth pattern of in-season and off-season Ross 308 broiler breeder flocks. Poultry Sci. 90, 2879-2887

Wiseman J., Lewis C.E., 1998. Influence of dietary energy and nutrient concentration on the growth of body weight and carcass components of broiler chickens. J. Agr. Sci. 131, 361-371 